UDC 621.039.674.3: 621.039.623

\title{
NOVEL HYBRID PILOT EXPERIMENT PROPOSAL FOR A FUSION-FISSION SUBCRITICAL COUPLED SYSTEM
}

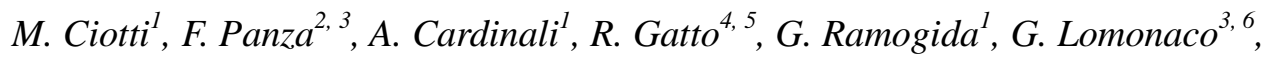 \\ G. Ricco $^{3,5}$, M. Ripani, ${ }^{3,5}$, M. Osipenko ${ }^{3}$ \\ ${ }^{I}$ ENEA Dipartimento Fusione e Tecnologie per la Sicurezza Nucleare, Divisione Fisica della Fusione, Frascati, Italy \\ ${ }^{2}$ ENEA Dipartimento Fusione e Tecnologie per la Sicurezza Nucleare, Divisione Tecnologie, Impianti e Materiali per la Fissione \\ Nucleare, Roma, Italy \\ ${ }^{3}$ Istituto Nazionale di Fisica Nucleare, Sezione di Genova, Genova, Italy \\ ${ }^{4}$ Sapienza Univ. Roma Dipartimento di Ingegneria Astronautica, Elettrica ed Energetica, Roma, Italy \\ ${ }^{5}$ Centro Fermi, Museo storico della fisica e centro studi e ricerche Enrico Fermi, Roma, Italy \\ ${ }^{6}$ GeNERG/DIMETEC Università degli studi di Genova, Genova, Italy
}

Fusion-fission hybrid systems (FFH) represent a coupling between a fusion device and a subcritical fission reactor driven by neutrons produced by fusion reactions. This kind of systems, in principle, can be useful for different purposes, for example, as energy amplifier or as nuclear waste burner. In this work, the preliminary characteristics and potentialities of a FFH based on a tokamak device characterized by high magnetic field $(B>9 \mathrm{~T})$ and high-density plasma $\left(n>10^{14} \mathrm{~cm}^{-3}\right)$ have been evaluated. During the years high magnetic field compact tokamaks have been designed, built and operated. Thanks to their characteristics, such as compactness, high field and high density plasma, these devices can produce intense neutron fluxes, and therefore are good candidates to be incorporated in FFH while operating in a sub-ignited regime. An additional advantage is that their design is based on relatively simple existing technology. In this work, a coupling between a tokamak (operating in DD-mode) and a subcritical molten salt fission blanket has been proposed. Molten salt reactor could be adapted for this purpose and could help the hybrid system to increase its energy balance. A model with a molten salt fission blanket ( $k_{\mathrm{eff}}=0.92, P=95 \mathrm{MW}$ ) instead of the lithium one, has been considered and studied in terms of neutronic evaluations. Presented preliminary numerical calculations based on a neutron Monte-Carlo code confirm the potentialities of the system.

Key words: Fusion-fission hybrid system, subcritical molten salt fission blanket, nuclear waste burner, compact tokamak with high magnetic field and high density plasma, neutron Monte-Carlo code.

DOI: 10.21517/0202-3822-2021-44-2-57-64

\section{НОВОЕ ПРЕДЛОЖЕНИЕ О РАЗРАБОТКЕ ЭКСПЕРИМЕНТАЛЬНОЙ ПОДКРИТИЧЕСКОЙ ГИБРИДНОЙ УСТАНОВКИ СИНТЕЗА-ДЕЛЕНИЯ}

\author{
М. Чиотти ${ }^{1}$, Ф. Панза ${ }^{2,3}$, А. Кардинали', Р. Гатто ${ }^{4,5}$, Д. Рамогида ${ }^{1}$, Д. Ломонако, ${ }^{3,6}$, \\ Д. Рикко ${ }^{3,5}$, М. Рипани ${ }^{3,5}$, M. Осипенко
}

\begin{abstract}
${ }^{I}$ Национальное агентство по новым технологиям, энергии и устойчивому экономическому развитию (ENEA), Отделение термоядерного синтеза и технологий ядерной безопасности, Отдел физики термоядерного синтеза, Фраскати, Италия ${ }^{2}$ Национальное агентство по новым технологиям, энергии и устойчивому экономическому развитию (ENEA), Отделение термоядерного синтеза и технологий ядерной безопасности, Отдел технологий, установок и материалов для ядерного деления, Рим, Италия ${ }^{3}$ Национальный институт ядерной физики, Генуэзское отделение, Генуя, Италия

${ }^{4}$ Сапиенца - Римский университет, Отдел технологических проблем астронавтики, электротехники и энергетики, Рим, Италия ${ }^{5}$ Центр им. Ферми, Музей истории физики и Центр исследований им. Энрико Ферми, Рим, Италия

${ }^{6}$ GeNERG / DIMETEC - Университет Генуи, Генуя, Италия
\end{abstract}

Гибридные системы синтеза-деления (ГССД) представляют собой объединение в одной установке термоядерного компонента и подкритического реактора деления, в котором реакция инициируется нейтронами, образующимися в результате реакций термоядерного синтеза. Такие системы, в принципе, могут быть полезны для различных целей, например, для увеличения производства энергии или сжигания ядерных отходов. В данной работе оценены характеристики и возможности ГССД на основе токамака с сильным магнитным полем $\left(B>9\right.$ Тл) и большой плотностью плазмы $\left(n>10^{14} \mathrm{~cm}^{-3}\right)$. В течение многих лет разрабатывались, строились и эксплуатировались компактные токамаки с сильным магнитным полем. Благодаря компактности, сильному магнитному полю и большой плотности плазмы такие токамаки могут генерировать интенсивные потоки нейтронов и, следовательно, являются хорошими кандидатами для включения в ГССД при их работе в подкритическом режиме. Их дополнительным преимуществом является то, что их конструкция основана на относительно простой существующей технологии. В этой работе был рассмотрен токамак, работающий на DD-реакции, с подкритическим бланкетом деления на основе расплавленной соли. Такой бланкет может увеличить выработку энергии в гибридной системе. Были изучены нейтронно-физические характеристики ГССД при замене литиевого бланкета бланкетом деления с расплавленной солью $\left(k_{\text {эф }}=0,92, P=95\right.$ МВт). Предварительные численные расчёты на основе нейтронного кода Монте-Карло подтверждают потенциальные возможности системы. 
Ключевые слова: гибридная система синтеза-деления, подкритический бланкет деления на основе расплавленной соли, ядерное уничтожение радиоактивных отходов, компактный токамак с сильным магнитным полем и большой плотностью плазмы, нейтронная вычислительная программа Монте-Карло.

\section{INTRODUCTION}

Fusion-fission hybrid systems (FFH) [1] represent a coupling between a fusion device and a subcritical fission reactor driven by neutrons produced by fusion reactions. This kind of systems, in principle, can be useful for different purposes, for example, as energy amplifier or as nuclear waste burner. In this work, we studied the characteristics and potentialities of a FFH based on tokamak device characterized by high magnetic field $(B>9 \mathrm{~T})$ and high-density plasma $\left(n>10^{14} \mathrm{~cm}^{-3}\right)$. During the years high magnetic field compact tokamaks have been built and operated (see for example FTU in Frascati (Italy) and C-MOD (MIT, Boston USA) and some like Ignitor [2-4] and Columbus projects [5, 6] have been designed. The latter two systems were originally conceived to explore the physics of burning plasmas with «Columbus» being a slightly enlarged version of Ignitor.

Thanks to their characteristics, such as compactness, high field and high density plasma, these devices can produce intense neutron fluxes [7], and therefore are good candidates to be incorporated in FFH [8] while operating in a sub-ignited regime. An additional advantage is that their design is based on relatively simple existing technology. Preliminary numerical calculations based on a neutron Monte-Carlo code are presented, confirming the potentialities of a FFH based on the coupling of a compact, high field tokamak with a fission region based on the molten salt concept as a preliminary device to start to gain experience in operating fusion fission subcritical coupled systems.

\section{IDEA AND BACKGROUND}

Several hybrid reactor configurations have been evaluated in the past years in order to verify conceptual ideas and machine potentialities.

The aim of this proposal is to evaluate the main characteristics for a new FFH device having as main goal, if realized, to short-cut the demonstration of the first energy producing system based on a fusion device. The achievement of this goal is currently foreseen in the fusion roadmap with the DEMO demonstrator, where a thermal power production of several hundred MW should be achieved for a relatively long time, but still in pulsed mode. On the other hand, DEMO overall energy balance [9], due to the large amount of needed power for re-circulation, for cryogenic cooling under intense high energy radiation flow, to additional power systems and, in general to its high technological complexity level, may not be necessarily positive. In addition, the roadmap for such a pure fusion demonstrator is still affected by several physical and technological challenging problems [10] some of them far to be solved, with at least 10 years of ITER operating time and IFMIF/DONES material testing, i.e. probably far away in this century.

In this paper, an experimental machine configuration, ready to be designed for a relevant net thermal power production demonstration is presented, with as much as simple and cheap solutions as possible. This device could be the first hybrid experimental system to be realized with the possibility to produce a relevant quantity of power (comparable to DEMO) starting from a fusion system. With this option the cost, realization time, overall system complexity, and consequently affordability, will be extremely reduced. This machine, in principle, could ensure a positive power net balance due to the lack of strong power needs. Additional heating, in fact, is not essential to the ignition (or at least a remarkable neutron rate production), that could be reached by Ohmic heating alone. The presence of a few MW (3-5 MW) of ICRH system will expand the capabilities of the device.

This new proposed configuration has few open points from both the physical and technological point of view, and its detailed planning and construction could be started in a relatively short time.

According to these guidelines a fusion compact, high density, high magnetic field non superconducting machine has been considered. The main consequences of this choice are the following: i) cheapness: machine compactness together with the use of normal copper magnets reduce the cost and the complexity of the machine; ii) possibility to operate even in DD-mode with acceptable neutron production [11]. High density compact machine can achieve a neutron production useful for a first experimental power generation test, if coupled with a fission system as shown hereafter. The DD-regime reduces the system complexity caused by the management of large 
quantities of tritium and overcome the possible uncertainty on the lack of tritium for the starting of the operations (one of the DEMO challenges); in addition, due to DD operations, it would be possible to replace the original lithium blanket for tritium production with a blanket filled with circulating liquid molten salts mixed with fission elements placed partly inside the vacuum vessel, for higher neutron flow.

On the other hand, the non-superconducting choice limits the discharge time in a way non-compatible with a real reactor needs, limiting this system to the exclusive purpose of a demonstrator able to start the exploration of the hybrid experimental configuration. In addition, the generation of DD $2.45 \mathrm{MeV}$ neutrons, instead of the DT $14 \mathrm{MeV}$, reduces the fission rate of $45 \%$ due to a reduced $n$-U235/238 cross-section. Even with these limits the configuration is able to produce in principle a relevant amount of power.

In Table I it is reported a parameter comparison between compact high-magnetic field tokamaks, which may be expected to be well-suited as neutron sources for hybrid systems (FIRE, Ignitor, Columbus), and the ITER tokamak presently under construction.

$\mathrm{T}$ a $\mathrm{b} 1 \mathrm{e}$ 1. Comparison between ITER, FIRE, Ignitor and Columbus main parameters

\begin{tabular}{|c|c|c|c|c|}
\hline Relevant parameters & ITER & FIRE & Ignitor & Columbus \\
\hline Pulse flat top $t_{\text {pulse }}, \mathrm{s}$ & 400 & 20 & 6 & 11.4 \\
\hline Minor radius $a, \mathrm{~m}$ & 2 & 0.595 & 0.47 & 0.535 \\
\hline Peak el. temperature $T_{e 0}, \mathrm{keV}$ & 19 & 11 & 10.5 & 11.5 \\
\hline Peak ion temperature $T_{i 0}, \mathrm{keV}$ & 19 & 11 & 10.5 & 10.5 \\
\hline Peak density $n, \mathrm{~m}^{-3}$ & $10^{20}$ & $5 \times 10^{20}$ & $9 \times 10^{20}$ & $9.5 \times 10^{20}$ \\
\hline Profile parameter $\alpha_{\mathrm{T}}$, parab & 1 & 1 & 2 & 2 \\
\hline Purity parameter $Z_{\mathrm{eff}}$ & 1.7 & 1.4 & 1.2 & 1.2 \\
\hline DD-neutron yield $Y_{\mathrm{DD}}, \mathrm{n} / \mathrm{s}$ & $10^{18}$ & $10^{17}$ & $10^{17}$ & $10^{18}$ \\
\hline DT-neutron yield $Y_{\mathrm{DT}}, \mathrm{n} / \mathrm{s}$ & $10^{20}$ & $10^{19}$ & $10^{20}$ & $10^{20}$ \\
\hline
\end{tabular}

\section{COMPACT DEVICE IN DD OPERATION MODE}

Due to its physics characteristics, high magnetic field compact tokamaks can generally operate both in DT- and in DD-mode. Here we focus on the latter mode of operation, which has the advantage of not needing a tritium breeding region in addition to the fission blanket, to have an idea of the potential performances of DD-operational mode.

A simple evaluation of the neutron emission yield has been performed. Considering, for example, the following plasma parameters: i) density $n_{e}=10^{15} \mathrm{~cm}^{-3}$ with parabolic profile; ii) $\langle\sigma \mathrm{v}\rangle=9 \times 10^{-20} \mathrm{~cm}^{3} / \mathrm{s}$ (Fig. 1); iii) $V_{\text {plasma }}=$ $=2.5 \times 10^{7} \mathrm{~cm}^{3}$; iv) $T_{\text {peak }} \approx 10 \mathrm{keV}$ with parabolic squared profile (note that ion and electron temperature at that plasma density are equivalent); v) no additional heating; the reaction rate can be calculated as: $R=n^{2} / 2\langle\sigma \mathrm{v}\rangle V_{\text {plasma }}=2 \times 10^{18} \mathrm{DD} / \mathrm{s}$. Since two equiprobable production channels are possible for the DD-reaction: i) $\mathrm{D}+\mathrm{D} \rightarrow{ }^{3} \mathrm{He}+n$; ii) $\mathrm{D}+\mathrm{D} \rightarrow{ }^{3} \mathrm{H}+p$; the neutron yield is about $Y=10^{18} \mathrm{n} / \mathrm{s}$.

Considering $E=3.27 \mathrm{MeV}\left({ }^{3} \mathrm{He}+n\right)$ and $4.03 \mathrm{MeV}\left({ }^{3} \mathrm{H}+p\right)$ as emitted energies for both production channels, fusion power can be estimated as $1.16 \mathrm{MW}$.

The design of a device like high magnetic field compact tokamak must be adapted to the requirements and goals of a FFH. In this contest, flat-top and cooling time duration represent crucial parameters for this configuration and have to be optimized in order to avoid molten salts freezing or complex heat exchanger addition to evacuate the excess heating.

New materials for the magnets might also be considered in order to increase magnetic flux availability and flat top duration, and the mode of operation (plasma temperature and density) should be adjusted to fit the requirements of a FFH.

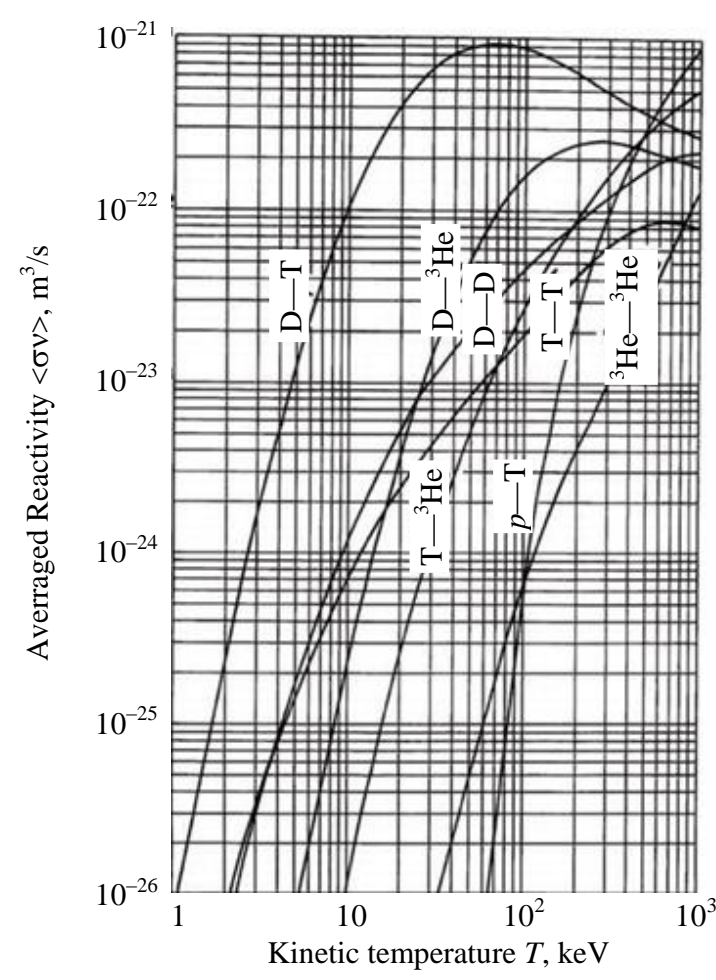

Fig. 1. $\langle\sigma v\rangle$ reaction rate as a function of plasma temperature for several fusion reactions 


\section{FUSION-FISSION HYBRID COUPLING}

On the basis of the considerations presented in the previous paragraphs, high field tokamak characteristics fit in a very good way with hybrid device requirements.

For the fusion plasma, an adaptation of the parameters to the requirements of an FFH is necessary, and this task will not be pursued here. For the fission zone, the following two main solutions could be considered:

- traditional reactor (with fuel rods) inside an external blanket, cooled by water;

— molten salt reactors (MSR) $[12,13]$ with fissile/fertile elements dissolved in the molten salt fluid.

Traditional reactors have the advantage in terms of technological knowledge and feasibility coming from decades of operation, but, in this kind of nuclear system, material stresses could represent a weak point especially for fuel rods cladding and structure. In particular, the pulsed behavior of the fusion machine could induce failures in the rod cladding. On the other side MSR solution could be better coupled to the tokamak geometry with the positioning of the blanket entirely, or partially, inside the machine. This has the advantage to intercept all the plasma produced neutrons and to shield the external structure from them.

There are many studies concerning MSR with different characteristics and designs, traditional or breeders, using many kinds of salt mixtures depending from the neutron spectrum inside the core (fast or moderated) [14-18].

The schematic view of MSR is reported in Fig. 2, in which it is possible to observe the molten salt circuit passing through the fission core and then in the heat exchanger loop.

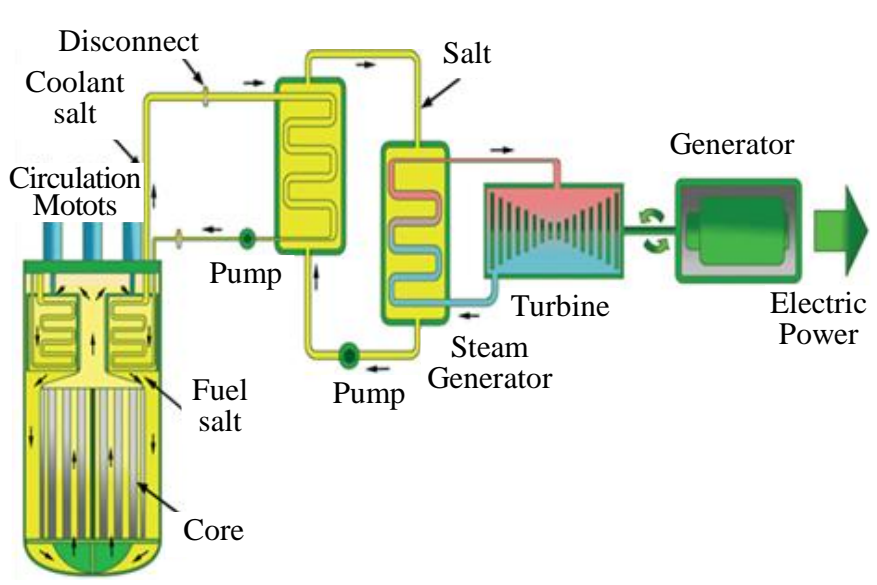

Fig. 2. MSR schematic view in which it is possible to observe the primary fuel loop passing through the reactor core, the secondary and the tertiary loops tuations will not be able to reach supercriticality.

\section{SIMPLE HYBRID SYSTEM PRELIMINARY SIMULATIONS}

In order to gain a preliminary understanding on the performances of the proposed hybrid system, a simplified simulation model has been considered. The model, as shown in Fig. 3, is based on a high magnetic
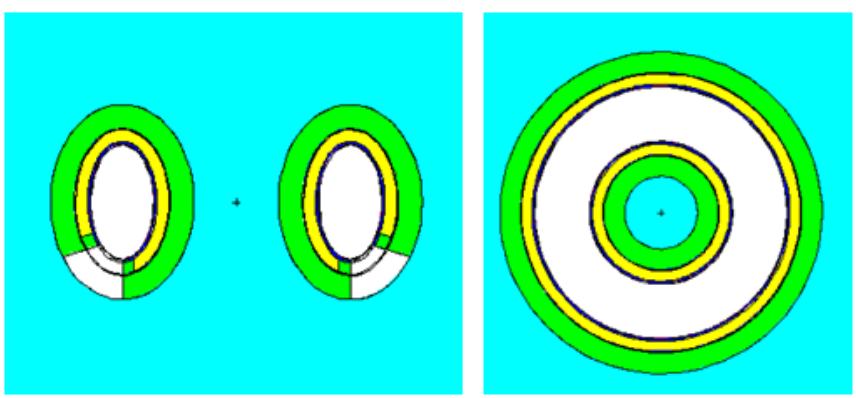

Fig. 3. FFH poloidal and toroidal sections sketches. Molten salt blanket ( ), steel vessel ( $\mid$ ), lead reflector ( $($ ) field compact tokamak device with the following geometric characteristics: major radius $R=200 \mathrm{~cm}$, minor radii $a=54 \mathrm{~cm}$ and $b=100 \mathrm{~cm}$ (vertical size of the plasma taking into account the elongation $\varepsilon=1.85)$. The first wall is composed by $1 \mathrm{~cm}$ thick tungsten, $3 \mathrm{~cm}$ thick AISI-316 followed by $29 \mathrm{~cm}$ thick molten salt fission blanket. This is supposed to be placed inside the machine vacuum vessel made with $2 \mathrm{~cm}$ steel. Just outside the vacuum vessel a $35 \mathrm{~cm}$ lead neutron reflector is positioned, to 
recover part of the out-flowing source or fission neutrons. In the following sketches a poloidal section (see Fig. 3) is shown with a void sector representing the space for divertor (not designed in this model and not necessarily required) positioning (in white).

The simulations have been performed by using the Monte-Carlo code MCNP6.1 with ENDF/BVII.0 libraries. For effective multiplication factor $\left(k_{\text {eff }}\right)$ evaluation KCODE mode has been used, while, for neutron and fluxes calculations SDEF mode have been considered.

The isotropic neutron source (from DD-fusion reactions) emitting $Y=10^{18} \mathrm{n} / \mathrm{s}$ over $4 \pi$ solid angle has been implemented uniformly on a circumference passing from the center of the torus as shown in Fig. 4.

$a$

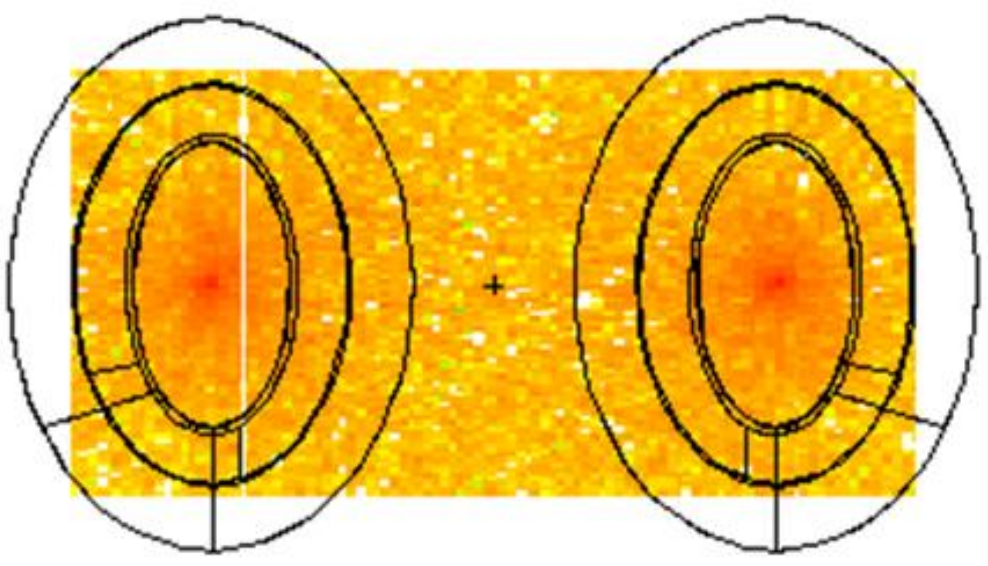

$b$

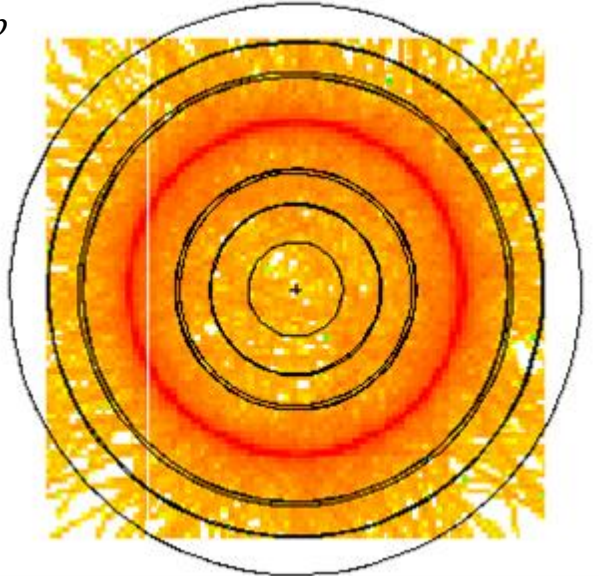

Fig. 4. Poloidal $(a)$ and toroidal $(b)$ views of the neutron emission from the circumference passing from the center of the torus

For this model, it has been considered a $34.5 \mathrm{~cm}$ thick fission blanket filled with molten salt mixture $\mathrm{LiF}-$ $\mathrm{NaF}-\mathrm{UF}_{4}(44.48 \%, 24.12 \%, 31.40 \%)$ molten $\%$ with $3.4 \mathrm{~g} / \mathrm{cm}^{3}$ density and the following mass composition [19]: $13.5 \%{ }^{235} \mathrm{U} ; 48.5 \%{ }^{238} \mathrm{U} ; 2 \%{ }^{7} \mathrm{Li} ; 31 \%{ }^{19} \mathrm{~F} ; 6 \%{ }^{23} \mathrm{Na}$.

The effective multiplication factor for this fission system results to be about 0.92 (in order to guarantee a high safety level), the integral neutron flux averaged on the whole molten salt volume is about $5,85 \times 10^{13} \mathrm{n} /\left(\mathrm{cm}^{2} \cdot \mathrm{s}\right)$ and the thermal power level is about $95 \mathrm{MW}_{\text {th }}$ (assuming a neutron yield of $10^{18} \mathrm{n} / \mathrm{s}$ ).

In this scenario, the energy distribution for the neutron flux averaged on the whole molten salt volume is shown in Fig. 5.

A map of the integral flux intensities in the hybrid system is shown in Fig. 6.

In Table 2, the integral flux and the integral flux evaluated for three energy bins with their relative percentages in terms of absolute flux are reported to have a quantitative idea of the neutron energy distribution inside the fission blanket.

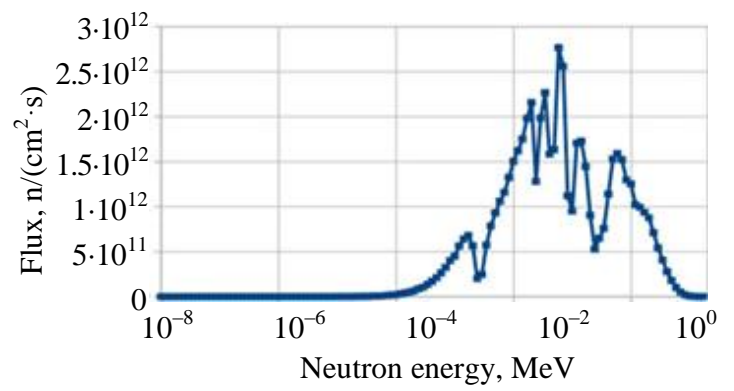

Fig. 5. Neutron energy distribution averaged over the whole molten salt volume
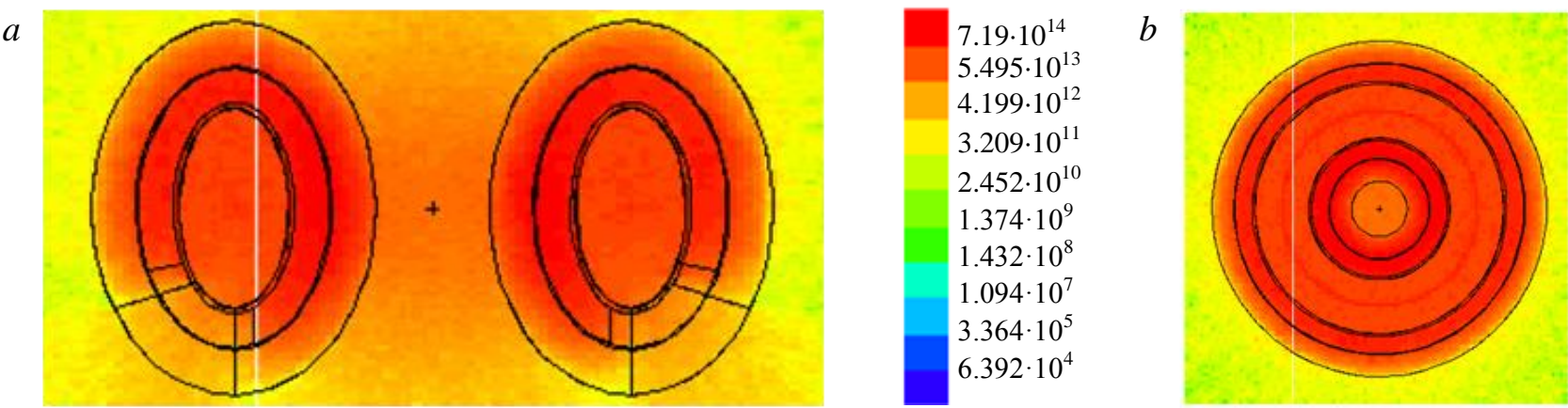

Fig. 6. Poloidal (a) and toroidal $(b)$ integral flux intensities in the hybrid system in the legend the flux intensities are reported in $\mathrm{n} /\left(\mathrm{cm}^{2} \cdot \mathrm{s}\right)$

$\mathrm{T}$ a $\mathrm{b} 1$ e 2 . Flux values for different energy bins with their relative percentage with respect to the integral one

\begin{tabular}{l|c|c|c|c}
\hline \multicolumn{1}{c|}{ Parameter } & Integral & $<1 \mathrm{eV}$ & $1 \mathrm{eV}-100 \mathrm{keV}$ & $>100 \mathrm{keV}$ \\
\hline Flux, $\mathrm{n} /\left(\mathrm{cm}^{2} \cdot \mathrm{s}\right)$ & $5.85 \times 10^{13}$ & $7.36 \times 10^{7}$ & $2.54 \times 10^{13}$ & $2.31 \times 10^{13}$ \\
Percentage, $\%$ & 100.0000 & 0.0001 & 60.4550 & 39.5448 \\
\hline
\end{tabular}


Such a fission blanket can provide a relatively high intensity flux with a good component in the range of fast reactors.

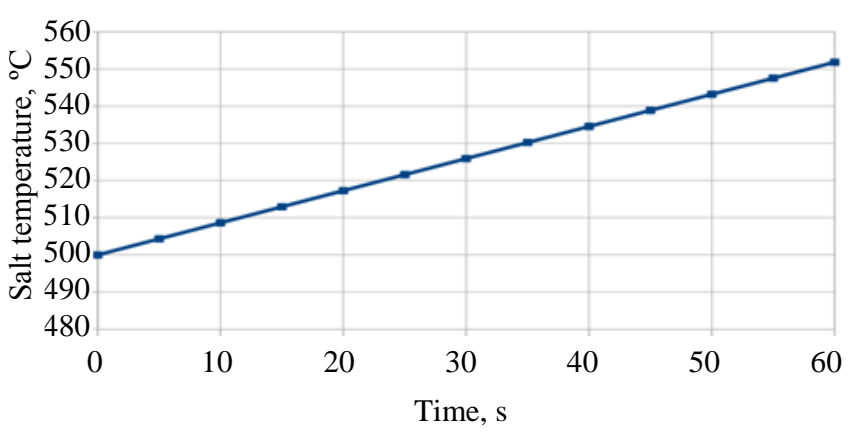

Fig. 7. Salt temperature increase as a function of shot duration

To have a more detailed and quantitative evaluation, starting from a temperature of about $500{ }^{\circ} \mathrm{C}$ (higher than fusion temperature) and considering the thermal power generated inside the salt mixture $\left(95 \mathrm{MW}_{\text {th }}\right)$ in stationary situation, the temperature increase as a function of pulse duration is shown in Fig 7.

An optimization regarding the pulse and the cooling time durations can be fundamental for the definition of the hybrid device operation mode in a more detailed model. In this framework, the magnets have to be actively cooled by liquid nitrogen flow during and in between the pulses as already done in the FTU machine [20]. Thermal insulators are still not considered in this preliminary version, but in a more detailed work, could be considered as a fundamental component of the system.

This simple analysis has to be better detailed but could highlight the possible compatibility between a high magnetic field tokamak and a molten salt fission blanket in order to start to gain experimental confidence with a simple fusion fission coupled system with increasing level of criticality.

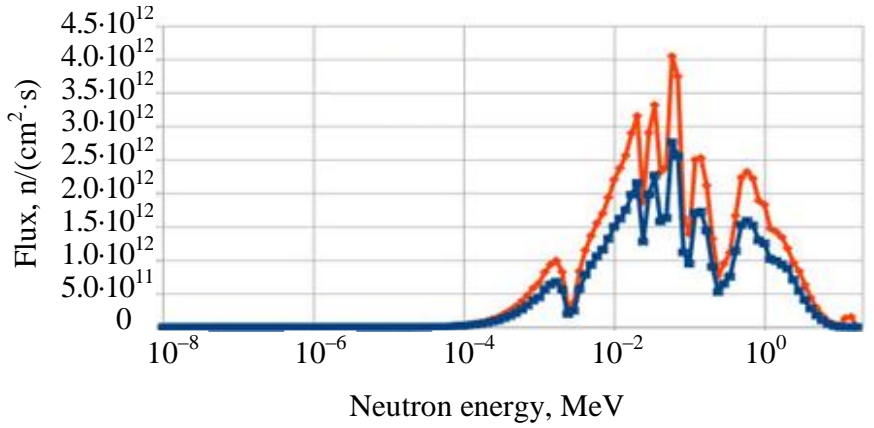

Fig. 8. Neutron energy distributions averaged over the whole molten salt volume for DD source (-) and for DT source (-)

To have an idea of the differences due to the use of $14.1 \mathrm{MeV}$ neutrons instead of considering $2.45 \mathrm{MeV}$, (as briefly recalled above), the comparison of the neutron spectra sampled inside the fission blanket obtained starting from DD- and DT-fusion reactions is reported in Fig. 8.

Neutron integral flux and thermal fission power in the case of DT-fusion source are $45 \%$ higher than in the case of DD-source (maintaining the same neutron intensity of $10^{18} \mathrm{n} / \mathrm{s}$ for both cases).

From this comparison, performed by maintaining the same neutron intensity, the better behavior of DT-source is clear, $14.1 \mathrm{MeV}$ neutrons are more efficient for inducing fission reactions inside the fuel. Another important factor is that the neutron intensity is much higher for DT-fusion with respect to DD. In any case, for a first experimental demonstration DD fuel appears to be suitable to drive the fission system.

\section{CONCLUSIONS}

In this paper the idea of considering a tokamak neutron source operating with DD fuel coupled with a molten salts fission blanket for a fusion-fission hybrid system preliminary experimental activity has been described. This solution could represent a short-cut towards a first experimental system based on a fusion machine generating an appreciable value of power with a positive overall energy balance. In this way it could be possible to reach the fusion power experimental generation conceptual demonstration several decades ahead of schedule as foreseen in the mainstream fusion roadmap.

High field non-superconducting tokamaks, for their peculiar properties, can act as neutron sources for FFH due to their compactness, their relative technological simplicity and their high neutron emission. An optimization in parameter space is however required in order to adapt the original already existing (i.e. Columbus) high field tokamak design to the hybrid purposes. The simple and feasible technology represents a crucial point with regard the realization of a FFH pilot experiment. Configuration optimization could be performed by modifying the magnetic field intensity and by considering new solutions and materials for the molten salt reactor technolo- 
gies, but the proposed technologies are well tested and available and allow to start with a simple and cheap system the coupling studies between fusion sources and fission energy generation module.

A simplified model simulation has been performed by using the MCNP6.1 code concerning a $k_{\text {eff }}=0.92$. The results of these simulations provide some preliminary insights on the main neutron parameters concerning the fission blanket in terms of geometric characteristics, thermal power and fluxes. A power production of about $95 \mathrm{MW}_{\text {th }}$ has been calculated along the plasma shot duration, sufficient for the first relevant power production demonstration with a fusion based system. The simulations have given inputs on the required characteristics concerning the fusion device, the geometrical disposition and the neutron emission intensity, providing a starting point for the definition of a pilot FFH experiment, its main characteristics and its operation mode. An important point is represented by molten salt thermal cycle: from a preliminary evaluation seems that the high magnetic field tokamak operation characteristics can match in a good way with the thermal properties of the salt in stationary conditions also allowing to increase, step by step the $k_{\text {eff }}$ of the system. A fusion shot of about few tens of seconds in case of an increased $k_{\text {eff }}$ could theoretically reach a significantly higher power production. A proper design of the copper magnets cooling system can help to increase the flat-top duration and to reduce the cooling time, in order to improve the FFH operation mode.

Of course, additional studies for a further detailed planning are needed.

\section{REFERENCES}

1. Bethe H.A. The fusion hybrid. — Phys. Today, 1979, vol. 32 (5), p. 44-51.

2. Coppi B., Nassi M. and the Ignitor Project Group. Physics Criteria and Design Solutions for an Advanced Ignition Experiment, MIT Report PTP-92/16 R. L. E., Cambridge, MA, 1992.

3. Coppi B. et al. New developments, plasma physics regimes and issues for the Ignitor experiment. — Nucl. Fusion, 2013, vol. 53, p. 104013.

4. Coppi B. et al. Perspectives for the high field approach in fusion research and advances within the Ignitor program. - Nucl. Fusion, 2015, vol. 55, p. 053011.

5. Salvetti M., Coppi B. The Ignitor-Columbus Path in Fusion Research. — In: 51st Annual Meeting of the APS Division of Plasma Physics. Vol. 54, Atlanta, Georgia, November 2-6, 2009.

6. Coppi B., Salvetti M. Highlights of the Columbus Concept. Massachusetts Institute of Technology, Cambridge, MA 02139, MIT (R.L.E.) Report PTP 02/06, December 2002.

7. Bombarda F., Coppi B., Hartwig Z.S., Sassi M., Zucchetti M. Compact tokamaks as convenient neutron sources for fusion reactors materials testing. - Fusion Engineering and Design, 2011, vol. 86, p. 2632.

8. Velikhov E.P., Kovalchuk M.V., Ilgisonis V.I. et al. Nuclear power system based on fission and fusion reactors is the strategic line of nuclear power industry development. — Phys. Atom. Nuclei, 2018, vol. 81, p. 981—987.

9. Ciattaglia S., Federici G., Barucca L., Stieglitz R., Taylor N. EU DEMO safety and balance of plant design and operating requirements. Issues and possible solutions. - Fusion Engineering and Design, September 2019, vol. 146, Part B, p. 2184 -2188.

10. Donné A.J.H. The European roadmap towards fusion electricity. — Phil. Trans. R. Soc. A 377: 20170432, 2019.

11. Coppi B. Private Communication, 2020.

12. MacPherson H.G. The molten salt reactor adventure. - Nuclear Science and Engineering, 1985, vol. 90, p. 374-380.

13. Briggs R.B. MSR Program Semiannual Progress Report for the Period Ending, July 31, 1964. (ORNL-3708) (66.3 MB PDF), Oak Ridge National Laboratory, U.S. AEC_(published November 1964). Retrieved 2008-05-21.

14. Yamamoto T. et al. Steady State analysis of molten salt reactor in consideration of the effect of fuel salt flow. - In: 12 th International Conference on Nuclear Engineering. Arlington, Virginia, USA, April 25-29, 2004.

15. Nagy K. et al. Parametric studies on the fuel salt composition in thermal molten salt breeder reactors. — In: International Conference on the Physics of Reactors Nuclear Power: A Sustainable Resource Casino-Kursaal Conference Center, Interlaken, Switzerland, September 14-19, 2008.

16. Křepel J. et al. Molten salt fast reactor blanket design and proliferation resistance assessment. — In: 2014 22nd International Conference on Nuclear Engineering ICONE22 Prague, Czech Republic, July 7—11, 2014.

17. Nuttin A., Heuer D., Billebaud A., Brissot R., Giorni A. et al. Thorium fuel cycles: a graphite-moderated molten salt reactor versus a fast spectrum solid fuel system. - In: International Conference on Back-End of the Fuel Cycle. From Research to Solutions (GLOBAL 2001). Paris, France. Sep. 2001, 086 (8 p.).

18. Siemer D. Why the molten salt fast reactor (MSFR) is the «best» Gen IV reactor. — Energy Sci. Eng., 2015, vol. 3, p. 83-97.

19. Woolley R.D. System Studies of Fission-Fusion Hybrid Molten Salt Reactors. PhD diss., University of Tennessee, 2013; https://trace.tennessee.edu/utk_graddiss/2628. 
20. Migliori S., Bettinali L., Gasparotto M., Pizzuto A. Liquid nitrogen cooling system for FTU tokamak machine. — In: Proc. of the Twelfth International Cryogenic Engineering Conference. Southampton, UK, 12-15 July 1988, Butterworth-Heinemann, 1988, p. 93-97, ISBN 9780408012591.

\section{AUTHORS}

Marco Ciotti; responsible for the physics division, Fusion department. Member of the DTT project board; ENEA Dipartimento Fusione e Tecnologie per la Sicurezza Nucleare, Divisione Fisica della Fusione, Frascati, Italy, marco.ciotti@enea.it

Fabio Panza, Researcher, PhD; ENEA Dipartimento Fusione e Tecnologie per la Sicurezza Nucleare, Divisione Tecnologie, Impianti e Materiali per la Fissione Nucleare, Roma, Italy; Istituto Nazionale di Fisica Nucleare, Sezione di Genova, Genova, Italy fabio.panza@enea.it

Alessandro Cardinali, researcher, PhD; ENEA Dipartimento Fusione e Tecnologie per la Sicurezza Nucleare, Divisione Fisica della Fusione, Frascati, Italy, alessandro.cardinali@enea.it

Renato Gatto, Associate Professor; Sapienza Univ. Roma Dipartimento di Ingegneria Astronautica, Elettrica ed Energetica, Roma, Italy; Centro Fermi Museo storico della fisica e centro studi e ricerche Enrico Fermi, Roma, Italy, renato.gatto@uniroma1.it

Giuseppe Ramogida, researcher, PhD; ENEA Dipartimento Fusione e Tecnologie per la Sicurezza Nucleare, Divisione Fisica della Fusione, Frascati, Italy, giuseppe.ramogida@enea.it

Guglielmo Lomonaco, Associate Professor; Istituto Nazionale di Fisica Nucleare, Sezione di Genova, Genova, Italy; GeNERG/DIMETEC Università degli studi di Genova, Genova, Italy, guglielmo.lomonaco@ unige.it

Giovanni Ricco, senior associate, MSc in Physics; Istituto Nazionale di Fisica Nucleare, Sezione di Genova, Genova, Italy; Centro Fermi Museo storico della fisica e centro studi e ricerche Enrico Fermi, Roma, Italy, ricco@ge.infn.it

Marco Ripani, Director of Research, MSc in Physics; Istituto Nazionale di Fisica Nucleare, Sezione di Genova, Genova, Italy; Centro Fermi Museo storico della fisica e centro studi e ricerche Enrico Fermi, Roma, Italy, marco.ripani@infn.it

Mikhail Osipenko, staff scientist, PhD; Istituto Nazionale di Fisica Nucleare, Sezione di Genova, Genova, Italy, osipenko@ ge.infn.it

Received 15 January 2021

Revised 16 March 2021

Accepted 25 March 2021

Problems of Atomic Science and Technology Ser. Thermonuclear Fusion, 2021, vol. 44, issue 2, pp. 57-64 